\title{
Liquid Chromatography-Mass Spectroscopy and Liquid Chromatography-Ultraviolet/Visible Photodiode Array Analysis of Selected Colchicum Species
}

\author{
Ahmad A. Gharaibeh",*, Ala'a Al-Serini ${ }^{\mathrm{a}}$, Rana M. Qasaymeh ${ }^{\mathrm{b}}$, \\ Amani S. Ma'aya'h ${ }^{\mathrm{b}}$, Khaled Tawahac, Tamam El-Elimat ${ }^{\mathrm{b}, \mathrm{d}}$, and Feras Q. Alali ${ }^{\mathrm{b}, *}$ \\ a Department of Applied Chemistry, Faculty of Science and Arts, \\ Jordan University of Science and Technology, P. O. Box 3030, Irbid 22110, Jordan. \\ E-mail: agharaib@just.edu.jo \\ b Department of Medicinal Chemistry and Pharmacognosy, Faculty of Pharmacy, \\ Jordan University of Science and Technology, P. O. Box 3030, Irbid 22110, Jordan. \\ E-mail: falali@just.edu.jo \\ c Department of Pharmaceutical Sciences, Faculty of Pharmacy, The University of Jordan, \\ Amman 11942, Jordan \\ d Current address: Department of Chemistry and Biochemistry, \\ University of North Carolina at Greensboro, Greensboro, NC 27402, USA \\ * Authors for correspondence and reprint requests \\ Z. Naturforsch. 67c, 451-460 (2012); received September 21, 2011/July 22, 2012
}

An in-house strategy to dereplicate colchicinoid alkaloids was recently developed by our team. It aimed at quickly identifying Colchicum constituents using LC-MS (liquid chromatography-mass spectroscopy) and LC-UV/Vis PDA (liquid chromatography-ultraviolet/ visible photodiode array) techniques. In this project, our goal was to validate the developed method through analysing the alkaloid-rich fractions of three Colchicum species that had been previously studied phytochemically using the traditional bioactivity-guided fractionation methodology. The analysed species were Colchicum tauri Siehe ex Stefanoff, Colchicum stevenii Kunth, and Colchicum tunicatum Feinbr., all belonging to the family Colchicaceae. In addition to identifying the compounds previously isolated and characterized by the traditional methodology, the new strategy succeeded in tentatively identifying a set of known compounds, but new to the species.

Key words: Dereplication, Colchicinoids, LC-APCI-MS

\section{Introduction}

Most natural products drug discovery programs rely on a traditional bioactivity-guided fractionation approach. Although this approach succeeds in isolating most of the well-known drugs of natural origin, it is tedious, costly, time-consuming, and may end up in isolating previously known compounds (Ghisalberti, 1993; Kingston, 1996). In the field of natural products, interest has been growing in the last twenty years in developing fast and efficient strategies to enable the discrimination between previously isolated known compounds and new compounds at the level of the crude extract. This strategy which is termed dereplication is very important for the efficient use of human and financial resources. By adopting a suitable dereplication method, tedious and time-consuming isolation of previously known compounds can be avoided, and hence efforts are focused on the targeted isolation of compounds showing novel or uncommon spectroscopic features (Hostettmann et al., 2001; Wolfender et al., 2003). In a pioneering work, Corley and Durley (1994) developed strategies to search through scientific and technical network files using molecular weight, carbon count, structure fragments, and taxonomy for rapid identification of known compounds.

Hyphenated techniques, which can be defined as the coupling of high performance liquid chromatography (HPLC) separation technologies with on-line spectroscopic/spectrometric detection technologies, are the most commonly used techniques in dereplication strategies. Of these, liquid chromatography-mass spectroscopy (LC-MS) has a wide range of applications in the development of dereplication tools for the tentative identification of plant and microbial secondary metabolites (Ackermann et al., 1996; Alali and El-Alali, 2005; 
Carmona et al., 2006; Jin et al., 2006; Liau et al., 2007; Liu et al., 2007; Petsalo et al., 2006; Sarker and Nahar, 2012).

A dereplication strategy was recently introduced by our research group for the analysis of colchicinoid alkaloids using LC-MS and liquid chromatography-ultraviolet/visible photodiode array (LC-UV/Vis PDA) techniques (Alali et al., 2008a). Briefly, this strategy used a three-step approach. First, LC-MS was used to acquire the molecular ion and, hence, the molecular weight of the compound. These data were searched across natural product databases, particularly the Dictionary of Natural Products (Chapman \& Hall, London, UK; Version 15:2) and against a selfcompiled library of colchicinoid alkaloids. Next, LC-UV/Vis PDA analysis was used to acquire the $\mathrm{UV} / \mathrm{Vis}$ spectrum of a compound that serves as a fingerprint grouping each compound into one of the different structural classes that are typical for colchicine analogues. Finally, the mass fragmentation data and the chromatographic retention times (and hence, relative polarity) were used to identify the structures of the compounds. The developed method was used to analyse Colchicum brachyphyllum Boiss. \& Haussk. ex Boiss. (Colchicaceae), a Colchicum species that has been previously studied phytochemically in our laboratory (Alali et al., $2005,2008 b$ ). The interesting results obtained by the dereplication method encouraged us to investigate three Colchicum species, previously studied with the bioactivity-guided fractionation approach, applying the above described method to further validate our method and to detect the presence of any interesting compounds that were not separable at the preparative level.

The alkaloid-rich fractions of Colchicum tauri Siehe ex Stefanoff, Colchicum stevenii Knuth, and Colchicum tunicatum Feinbr. were analysed using our dereplication strategy (Alali et al.,2008a). Using the bioactivity-guided fractionation approach, the following compounds had previously been isolated: from C. tauri: (-)-colchicine, 2-demethyl-(-)-colchicine, 3-demethyl-(-)-colchicine, (-)-demecolcine, $N$-methyl-(-)-demecolcine, 3-demethyl- $N$-methyl(-)-demecolcine, $\beta$-lumicolchicine, 3-demethyl$\beta$-lumicolchicine, and apigenin (Alali et al., 2006a); from C. stevenii: (-)-colchicine, 2-demethyl-(-)-colchicine, $\beta$-lumicolchicine, cornigerine, isoandrocymbine, and $O$-methyl androcymbine (Al-Mahmoud et al., 2006); from C. tunicatum: (-)-colchicine, 3-demethyl-(-)-colchicine, cornige- rine, $\beta$-lumicolchicine, and (-)-androbiphenyline (Alali et al., 2006b). In the present study, we report compounds tentatively identified using the dereplication method and compare them with those isolated by the traditional bioactivity-guided fractionation methodology.

\section{Results and Discussion}

The alkaloid-rich fractions of corms, leaves, and flowers of C. tauri, and corms and leaves of $C$. stevenii and $C$. tunicatum, respectively, were analysed analytically as outlined in the Experimental Section using LC-MS and LC-UV/Vis PDA techniques. Fig. 1 shows typical LC-MS total ion chromatograms (TICs) of the analysed parts of $C$. tauri, C. stevenii, and C. tunicatum. The molecular ion for each peak of each part is shown in Fig. 2. Table I summarizes the $U V_{\max }$ and mass spectral data of each peak as well. The identified compounds were given consecutive numbers corresponding to the order of their elution during reversed phase (RP)-HPLC as well as the order of the investigated species and their parts as arranged in Fig. 1.

The (+)-APCI mass spectrum of peak 1 at $t_{\mathrm{R}}=$ $9.8 \mathrm{~min}$ of the corms of $C$. tauri showed a parent molecular ion at $\mathrm{m} / \mathrm{z} 372$ for $[\mathrm{M}+\mathrm{H}]^{+}, 28 \mathrm{Da}$ less than the analogous peak in (-)-colchicine (Figs. 1 and 2), and the compound was eluted earlier (i.e. it is more polar) than (-)-colchicine. The UV/Vis PDA spectrum had two absorption maxima at 245 and $354 \mathrm{~nm}$, implying structural similarities to (-)-colchicine. These data suggested that this compound was (-)-demecolcine (Alali et al., 2006a; Freyer et al., 1987). The (+)-APCI mass fragmentation spectrum of the molecular ion peak showed a peak at $\mathrm{m} / \mathrm{z} 341$ which was attributed to the ion $\left[\mathrm{MH}-\mathrm{NH}_{2} \mathrm{CH}_{3}\right]^{+}$, which was followed by loss of $\mathrm{CO}$ tropolonic to $m / z 313$.

In a way analogous to the identification of peak 1 , peaks $2,3,4,5,6,7,8,10,11,12,13,14,15$, and 18 were identified as $N$-methyl-(-)-demecolcine, 3-demethyl- $N$-methyl-(-)-demecolcine, 2-demethyl-(-)-colchicine, (-)-colchiciline or (-)-colchifoline, (-)-colchicine, $\beta$-lumi-(-)-colchicine, 2-demethyl-(-)-demecolcine or 3-demethyl-(-)demecolcine, 3-demethyl-(-)-colchicine, apigenin, (-)-isoandrocymbine, crociflorinone, $O$-methyl(-)-androcymbine, (-)-cornigerine, and (-)-colchiceine, respectively (Figs. 1 and 2 and Table I) (Alali et al., 2005, 2006a; Alali and El-Alali, 2005; 


\section{A) Colchicum tauri:}
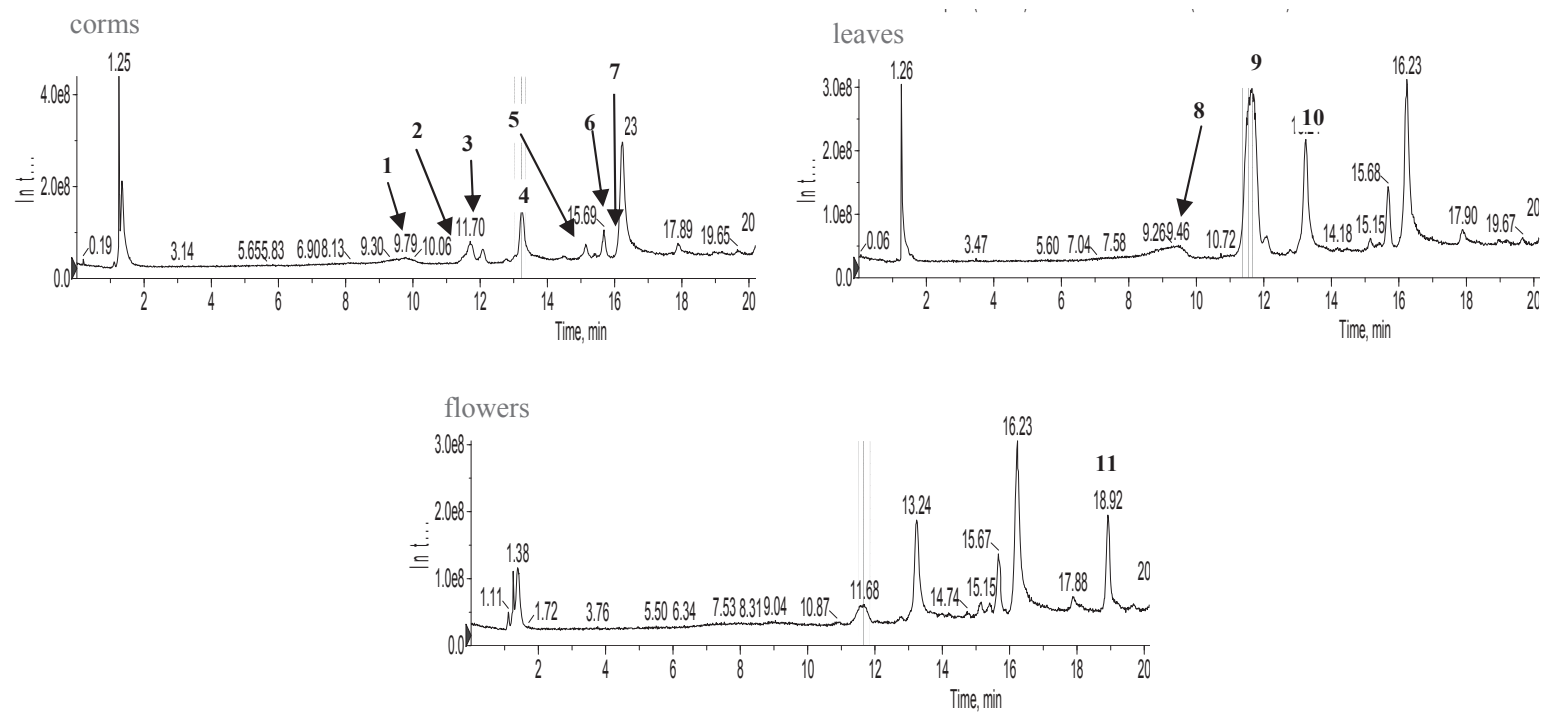

\section{B) Colchicum stevenii}
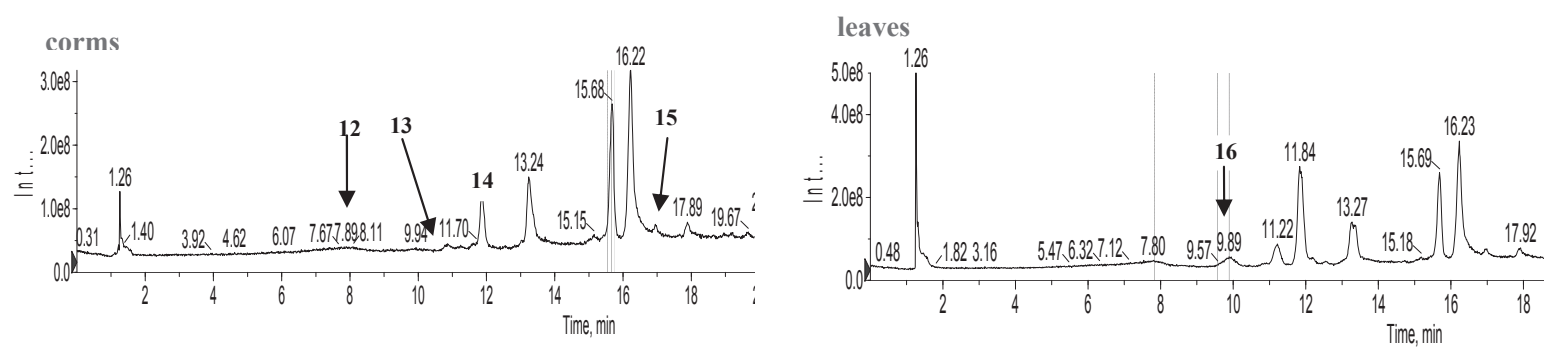

\section{C) Colchicum tunicatum:}
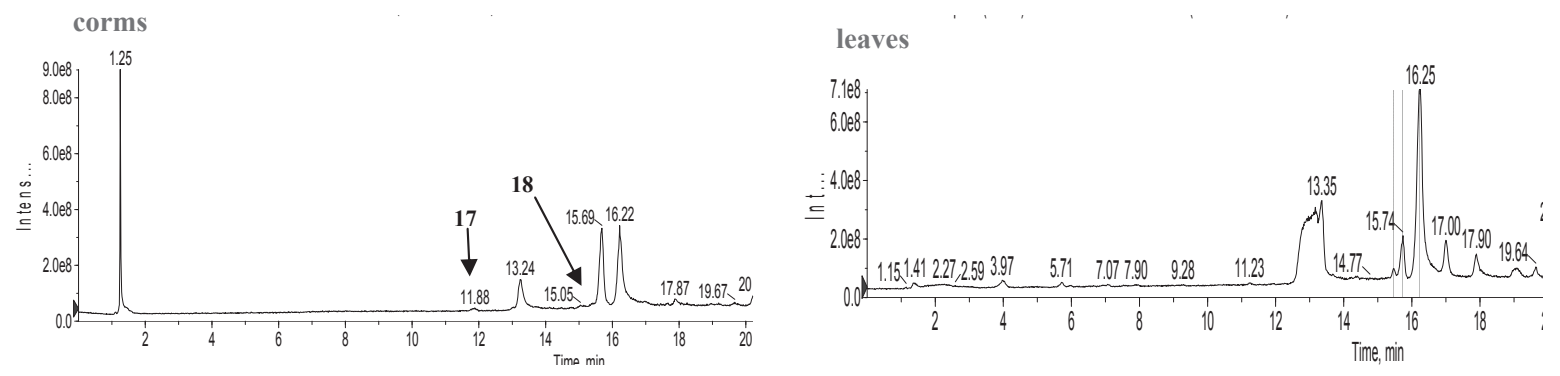

Fig. 1. (+)-APCI total ion chromatograms of the alkaloid-rich fractions of (A) C. tauri, (B) C. stevenii, and (C) C. tunicatum.

Al-Mahmoud et al., 2006; Chommadov et al., 1990; Freyer et al., 1987; O'Neil et al., 2001; Potesilova et al., 1977; Rosso and Zuccaro, 1998; Roth and Rupp, 1995; Turdikulov et al., 1974).
For $C$. tauri, we were unable to suggest a chemical structure for peak 9 at $t_{\mathrm{R}}=11.7 \mathrm{~min}$ in the flowers and leaves that showed a parent molecular ion at $m / z, 370$ for $[\mathrm{M}+\mathrm{H}]^{+}$. The retention 

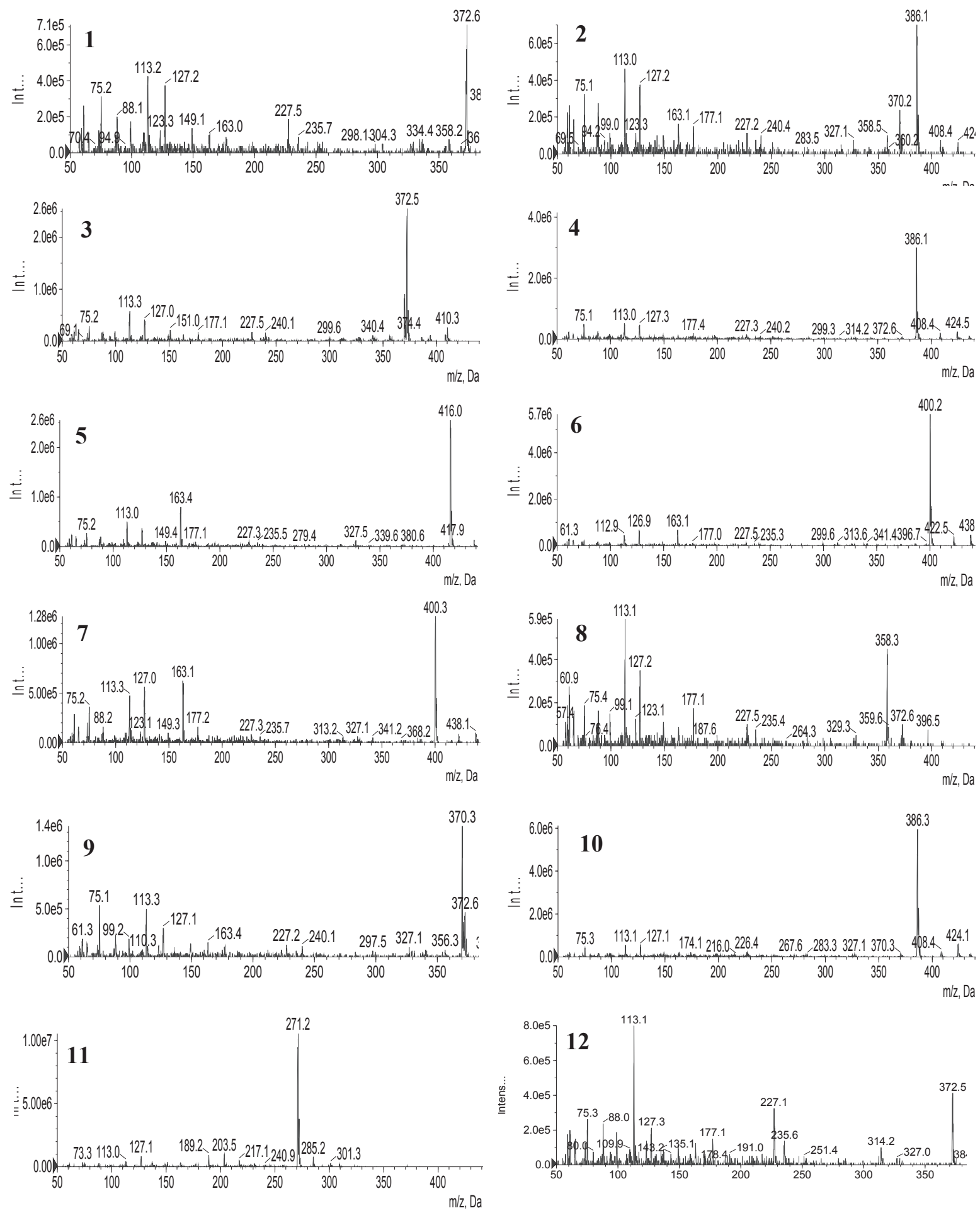

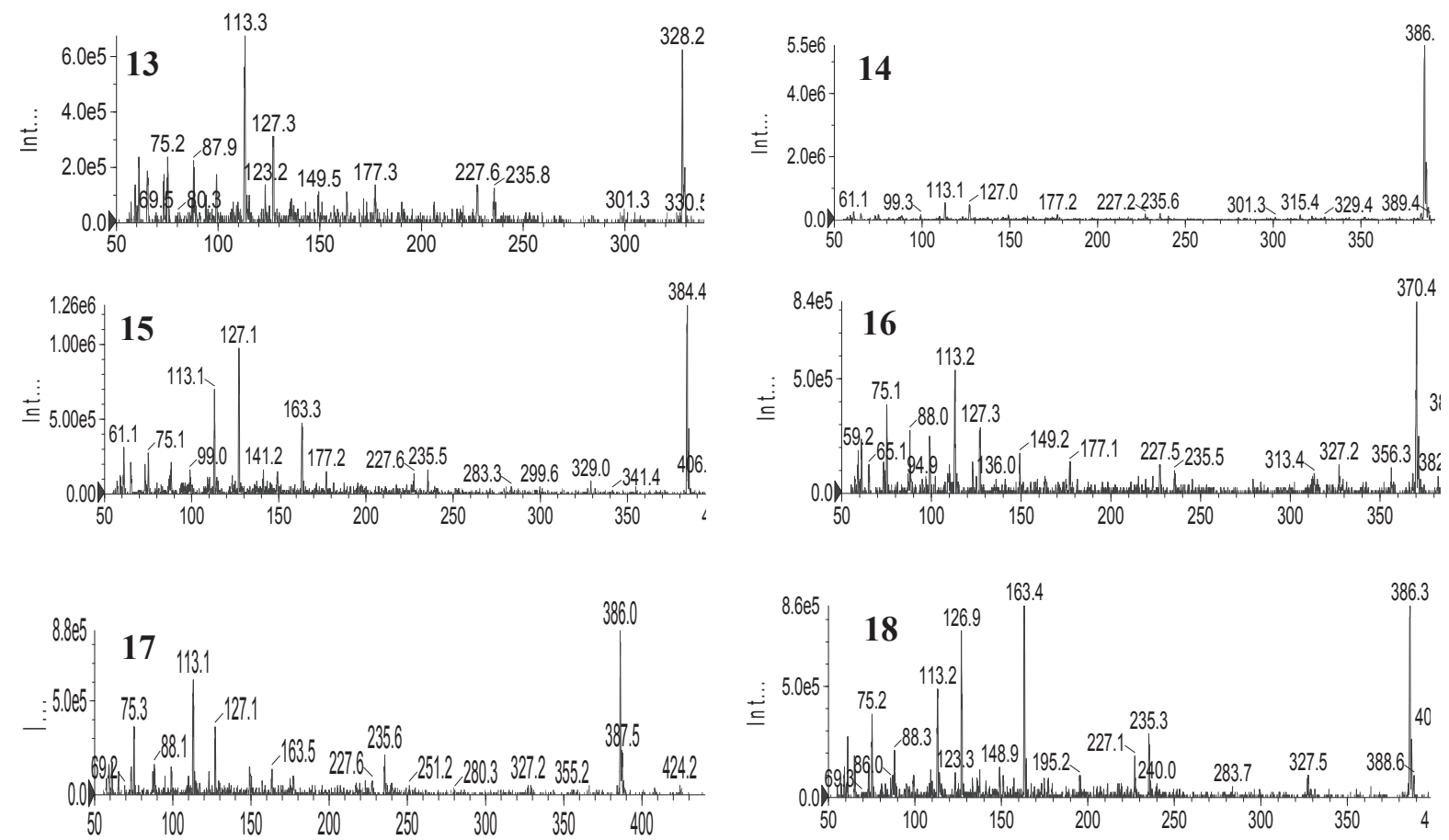

Fig. 2. (+)-APCI mass spectra of the TIC chromatographic peaks of C. tauri, C. stevenii, and C. tunicatum arranged based on the appearance of the corresponding chromatographic peaks in Fig. 1.

Table I. Retention times, $\mathrm{UV}_{\max }$, and mass spectral data of the (+)-APCI TIC chromatographic peaks.

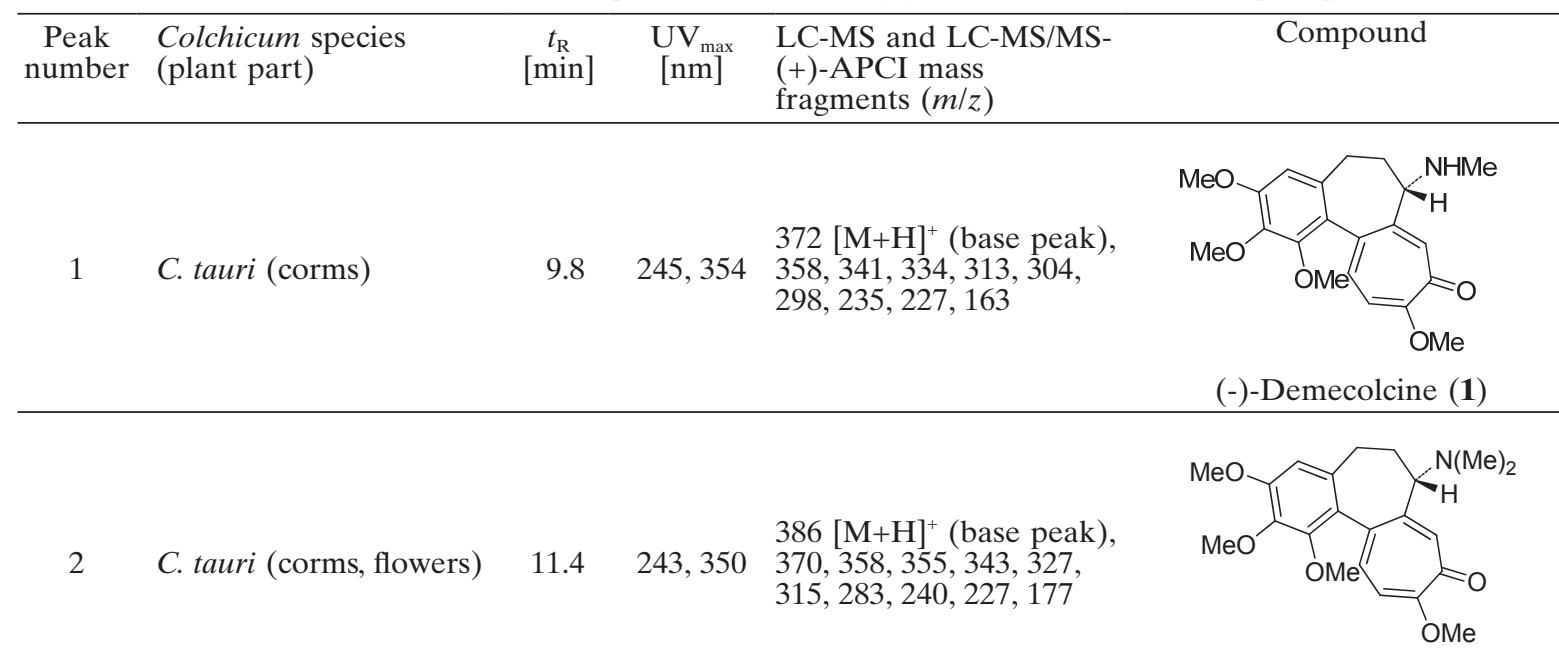


Table I continued.

\begin{tabular}{clccl}
\hline $\begin{array}{c}\text { Peak } \\
\text { number }\end{array}$ & $\begin{array}{l}\text { Colchicum species } \\
\text { (plant part) }\end{array}$ & $\begin{array}{c}t_{\mathrm{R}} \\
{[\mathrm{min}]}\end{array}$ & $\begin{array}{c}\mathrm{UV}_{\max } \\
{[\mathrm{nm}]}\end{array}$ & $\begin{array}{l}\text { LC-MS and LC-MS/MS- } \\
(+)-\mathrm{APCI} \text { mass } \\
\text { fragments }(\mathrm{m} / \mathrm{z})\end{array}$ \\
\hline & & & \\
& & & \\
3 & C. tauri (corms) & 11.7 & 244,356 & $\begin{array}{l}372[\mathrm{M}+\mathrm{H}]^{+}(\text {base peak), } \\
340,329,302,299,240, \\
\end{array}$ \\
& & & 227,177
\end{tabular}

Compound 227, 177<smiles>COc1ccc2c(c1)C(C(C)C)CCc1cc(O)c(OC)c(OC)c1-2</smiles>

3-Demethyl- $N$-methyl-(-)demecolcine (3)

$4 \quad$ C. tauri (corms, leaves) 13.2 C. stevenii (corms, leaves) 13.4
$386[\mathrm{M}+\mathrm{H}]^{+}$(base peak), 246, $354372,327,314,299,240$, 227,177<smiles>C=CN[C@@H]1CCc2cc(OC)c(O)c(OC)c2-c2ccc(OC)c(=O)cc21</smiles>

2-Demethyl-(-)-colchicine (4)<smiles>COc1cc2c(c(OC)c1OC)-c1ccc(OC)c(=O)cc1[C@H](NC(C)=O)[C@H](O)C2</smiles>

C. tauri (corms, leaves, flowers) C. stevenii (corms, leaves)
$15.2245,353$

$416[\mathrm{M}+\mathrm{H}]^{+}$(base peak), 327, 235, 227, 163
(-)-Colchiciline (5)<smiles>COc1cc2c(c(OC)c1OC)-c1ccc(OC)c(=O)cc1[C@H](NC(=O)CO)CC2</smiles>

(-)-Colchifoline (5)
C. tauri (corms, leaves, flowers)

$6 \quad$ C. stevenii (corms, leaves) C. tunicatum (corms, leaves)
$400[\mathrm{M}+\mathrm{H}]^{+}$(base peak), 247, $354341,313,299,282,235$, $227,177,163,126$<smiles></smiles>

(-)-Colchicine (6)
C. tauri (corms, leaves, 7 flowers)

C. stevenii (corms, leaves) C. tunicatum (corms)
$400[\mathrm{M}+\mathrm{H}]^{+}$(base peak), 15.8 225,273 368, 341, 327, 313, 235, 227, 177, 163, 127, 113

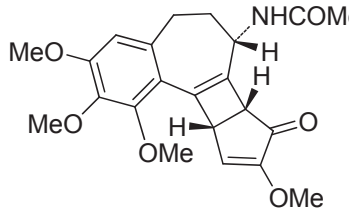

$\beta$-Lumi-(-)-colchicine (7) 
Table I continued.

\begin{tabular}{|c|c|c|c|c|c|}
\hline $\begin{array}{c}\text { Peak } \\
\text { number }\end{array}$ & $\begin{array}{l}\text { Colchicum species } \\
\text { (plant part) }\end{array}$ & $\begin{array}{c}t_{\mathrm{R}} \\
{[\mathrm{min}]}\end{array}$ & $\begin{array}{l}\mathrm{UV}_{\max } \\
{[\mathrm{nm}]}\end{array}$ & $\begin{array}{l}\text { LC-MS and LC-MS/MS- } \\
(+) \text {-APCI mass } \\
\text { fragments }(\mathrm{m} / \mathrm{z})\end{array}$ & Compound \\
\hline 8 & C. tauri (leaves) & 9.7 & 242,352 & $\begin{array}{l}358[\mathrm{M}+\mathrm{H}]^{+}, 329,327 \\
264,235,227,187,177\end{array}$ & 2-Demethyl-(-)-demecolcine (8) \\
\hline 9 & C. tauri (leaves, flowers) & 11.7 & ND & $\begin{array}{l}370[\mathrm{M}+\mathrm{H}]^{+} \text {(base peak), } \\
356,327,297,240,227, \\
163\end{array}$ & Unknown \\
\hline 10 & $\begin{array}{l}\text { C. tunicatum (corms, } \\
\text { leaves) } \\
\text { C. tauri (leaves, flowers) }\end{array}$ & $\begin{array}{l}13.2 \\
13.3\end{array}$ & 243,355 & $\begin{array}{l}386[\mathrm{M}+\mathrm{H}]^{+}(\text {base peak }) \\
327,253,235,227,163\end{array}$ & $\mathrm{MeO}$ \\
\hline
\end{tabular}

3-Demethyl-(-)-colchicine (10)

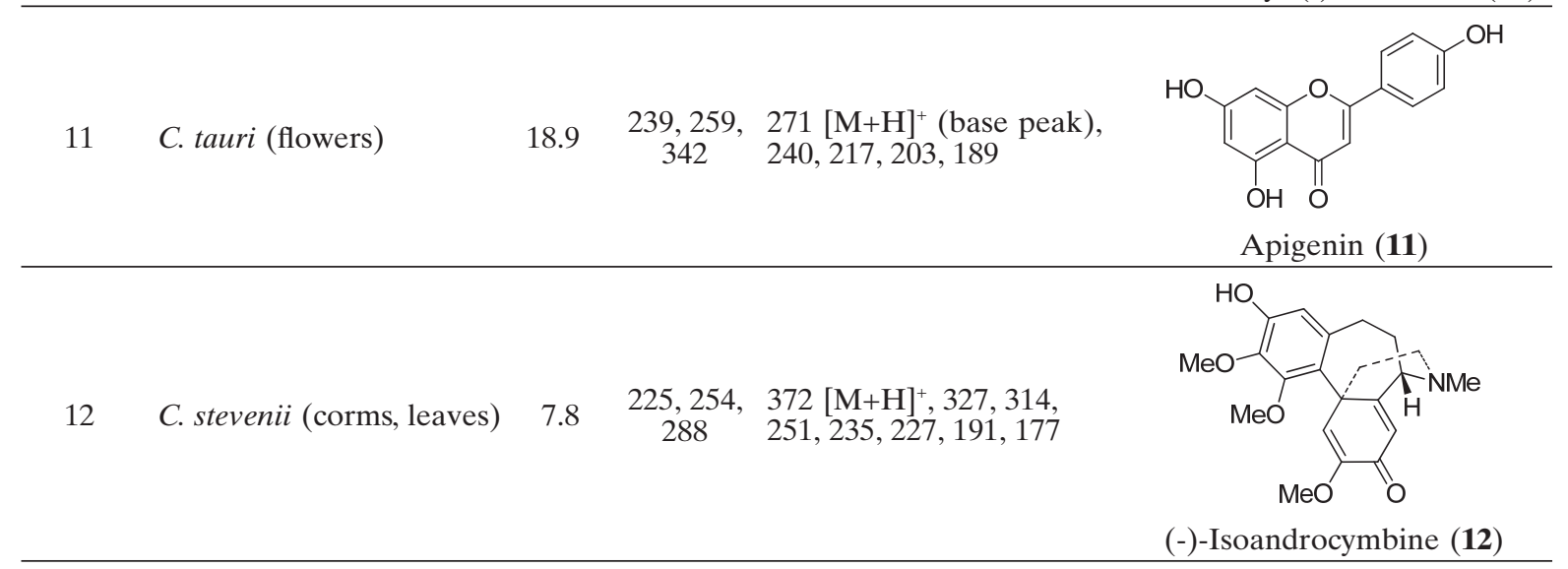


Table I continued.

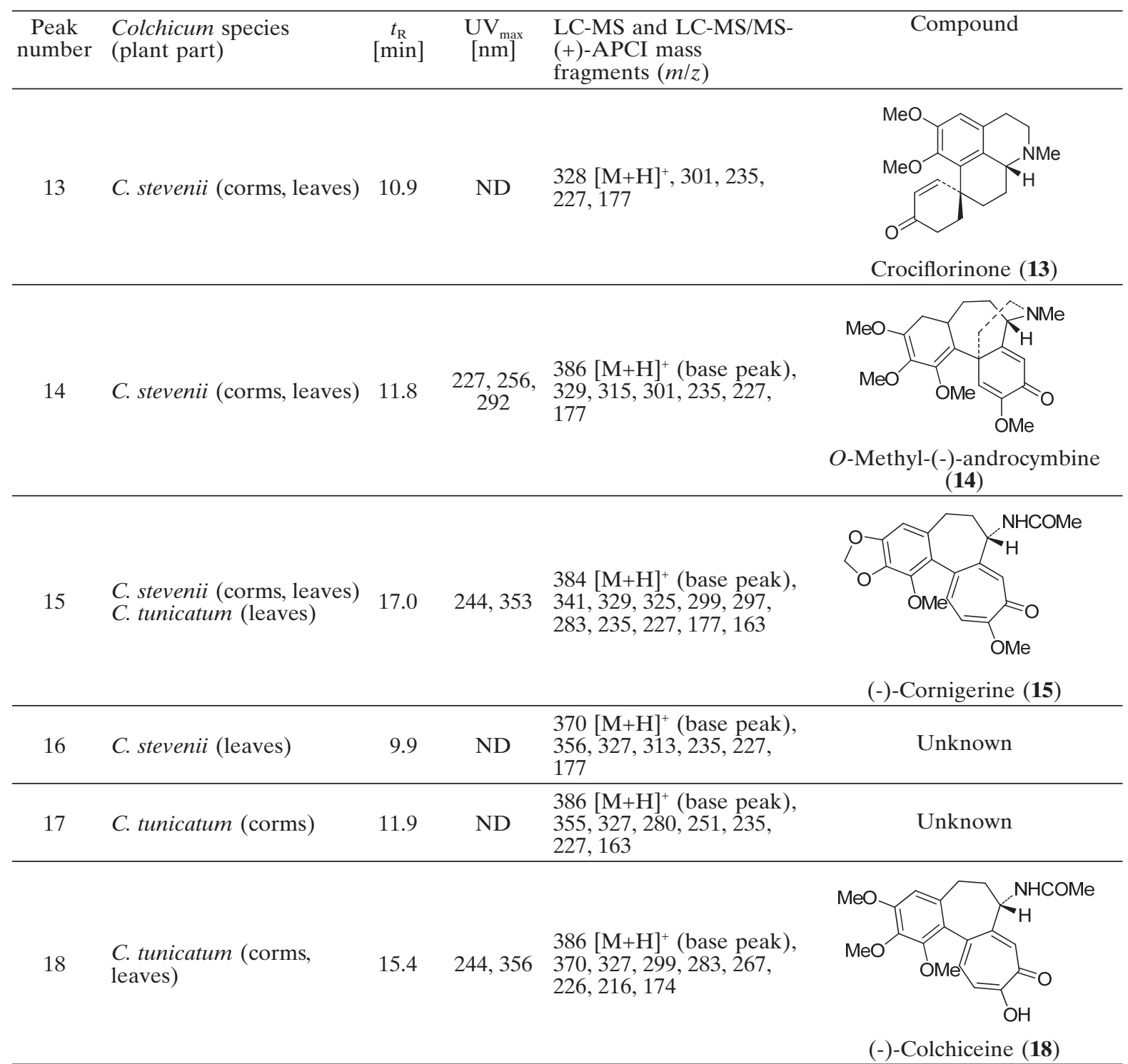

ND, not detected.

time and UV/Vis PDA spectra were not conclusive. For the same reasons, we were unable to suggest chemical structures for peak $16\left(t_{\mathrm{R}}=\right.$ $9.9 \mathrm{~min}$ ) in the leaves of $C$. stevenii and peak 17 $\left(t_{\mathrm{R}}=11.9 \mathrm{~min}\right)$ in the corms of $C$. tunicatum that showed molecular ion peaks at $\mathrm{m} / z, 370$ and 386, respectively.
Of the nine compounds previously isolated from C. tauri by bioactivity-guided fractionation (see Introduction) (Alali et al., 2006a), we were able to identify all except 3-demethyl- $\beta$-lumicolchicine. Moreover, we were able to tentatively identify two compounds new for the species, namely:3-demethyl(-)-demecolcine [or 2-demethyl-(-)-demecolcine], 
(-)-colchiciline [or (-)-colchifoline], in addition to one compound, which was not identified and thus considered unknown.

All six compounds previously isolated from $C$. stevenii (Al-Mahmoud et al., 2006) were identified here, and we were able to tentatively identify two new compounds, namely: (-)-colchiciline [or (-)-colchifoline] and crociflorinone, in addition to one compound which was not identified and thus considered unknown.

Of the five colchicinoids previously isolated from C. tunicatum (Alali et al. 2006b), four were identified here except for (-)-androbiphenyline. On the other hand, one compound new to the species was tentatively identified namely (-)-colchiceine, in addition to one compound which was not identified and thus considered unknown.

These findings, from the three studied species, clearly demonstrate the advantage of using LC-MS and LC-PDA dereplication strategies as powerful and economical tools for dereplication of natural products in crude plant extracts. Although it took around a year of hard and costly work to isolate and identify the active components from Colchicum species phytochemically, we were able to tentatively identify the majority of the constituents from the crude alkaloid fraction in a single linear analytical run. Moreover, the strategy was able to discriminate between previously isolated, known compounds and new compounds hitherto not described. Hence, the application of this strategy before setting out a large-scale isolation project is of great importance to avoid the tedious isolation of known constituents, and thus focus on the targeted isolation of constituents presenting novel or unusual spectroscopic features. In comparison with our already published paper (Alali et al., 2008a), in the current work, we used a different LC-MS instrument (triple quadrupole mass analyser rather than ion trap) in a different laboratory and operated by a different technician, and the results thus demonstrate the robustness of the developed method.

\section{Experimental}

\section{General}

LC-MS data were collected using an Applied Biosystems (Foster City, CA, USA) triple quadrupole LC-MS instrument (API 3200) operated in the APCI positive ionization mode and an Agilent 1200 series HPLC instrument (Santa Clara,
CA, USA). The separation was achieved using a Hypersil BDS $(125 \mathrm{~mm} \times 4 \mathrm{~mm} ; 5 \mu \mathrm{m})$ column (Thermo Electron, Auchtermuchty, UK). The mobile phase used was: (A) $\mathrm{H}_{2} \mathrm{O}$ acidified with $0.1 \%$ formic acid; (B) $\mathrm{MeOH}$. The flow rate was $1 \mathrm{~mL} / \mathrm{min}$ in the following gradient combinations: 0-2 min, $90 \%$ (v/v) A/10\% B; 2-27 min, $10 \%$ A/90\% B; 27-30 min $90 \%$ A/10\% B. The injection volume was $20 \mu \mathrm{L}$, and the total run time was $30 \mathrm{~min}$. The mass detector conditions were as follows: APCI positive ionization mode; full scan mode from $\mathrm{m} / \mathrm{z} 50$ to 800 ; corona discharge voltage, NC, $5 \mathrm{kV}$; APCI temperature, $500{ }^{\circ} \mathrm{C}$; gas flow rate, $5 \mathrm{~L} / \mathrm{min}$.

UV/Vis PDA spectra were obtained on an Agilent 1200 series HPLC instrument, equipped with an Agilent 1200 quaternary pump, a 1200 photodiode array detector in the range between 200 and $400 \mathrm{~nm}$, and a 1200 series auto-sampler. Mobile phase, flow rate, analytical column, injection volume, and run times were the same as those used for LC-MS.

Formic acid (extra pure) and methanol (HPLC grade) were obtained from Scharlau Chemie S.A. (Barcelona, Spain). (-)-Colchicine standard was purchased from Fluka Chemie (Buchs, Switzerland).

\section{Sample preparation and analysis}

The alkaloid-rich fractions of the different parts of C. tauri, C. stevenii, and C. tunicatum came from our earlier work (Al-Mahmoud et al., 2006; Alali et al., 2006a, b) and were stored in glass vials wrapped with aluminum foil, sealed with Parafilm ${ }^{\circledR}$ and maintained at $-2{ }^{\circ} \mathrm{C}$. For the dereplication studies, an aliquot of the alkaloid-rich fraction of each plant part $(2 \mathrm{mg})$ was dissolved in the mobile phase, filtered through a $0.45-\mu \mathrm{m}$ Teflon filter, and then transferred to 2-mL amber HPLC vials. A $20-\mu \mathrm{L}$ aliquot was injected into the LC-UV/Vis PDA and LC-MS systems. (-)-Colchicine standard was used for retention time matching.

\section{Acknowledgements}

The authors acknowledge the financial support from the Deanship of Scientific Research, JUST, Irbid, Jordan, and the technical help of Mr. Ashraf Al-Matalq, Pharmaceutical Research Center, JUST, Irbid, Jordan. 
Ackermann B. L., Regg B. T., Colombo L., Stella S., and Coutant J. E. (1996), Rapid analysis of antibiotic-containing mixtures from fermentation broths by using liquid chromatography-electrospray ionization-mass spectrometry and matrix-assisted laser desorption ionization-time-of-flight-mass spectrometry. J. Am. Soc. Mass Spectrom. 7, 1227-1237.

Al-Mahmoud M. S., Alali F. Q., Tawaha K., and Qasaymeh R. M. (2006), Phytochemical study and cytotoxicity evaluation of Colchicum stevenii Kunth (Colchicaceae): A Jordanian meadow saffron. Nat. Prod. Res. 20, 153-160.

Alali F. and El-Alali A. (2005), LC-MS analysis of corms of Colchicum hierosolymitanum (Colchicaceae). Acta Pharm. Turc. 47, 143-150.

Alali F. Q., El-Elimat T., Li C., Qandil A., Alkofahi A., Tawaha K., Burgess J. P., Nakanishi Y., Kroll D. J., Navarro H. A., III J. O. F., Wani M. C., and Oberlies N. H. (2005), New colchicinoids from a native Jordanian meadow saffron, Colchicum brachyphyllum: Isolation of the first naturally occurring dextrorotatory colchicinoid. J. Nat. Prod. 68, 173-178.

Alali F., Ma'aya'h A. S., Alkofahi A., Qandil A., Li C., Burgess J. P., Wani M. C., and Oberlies N. H. (2006a), A new colchicinoid from Colchicum tauri, an unexplored meadow saffron native to Jordan. Nat. Prod. Commun. 1, 95-99.

Alali F., Tawaha K., El-Elimat T., Qasaymeh R., Li C., Burgess J. P., Nakanishi Y., Kroll D. J., Wani M., and Oberlies N. H. (2006b), Phytochemical studies and cytotoxicity evaluations of Colchicum tunicatum Feinbr and Colchicum hierosolymitanum Feinbr (Colchicaceae): Two native Jordanian meadow saffrons. Nat. Prod. Res. 20, 558-566.

Alali F., Gharaibeh A., Ghawanmeh A., Tawaha K., and Oberlies N. H. (2008a), Colchicinoids from Colchicum crocifolium Boiss.: A case study in dereplication strategies for (-)-colchicine and related analogs using LC-MS and LC-PDA techniques. Phytochem. Anal. 19, 385-394.

Alali F. Q., Tahboub Y. R., Al-Daraysih I. S., and El-Elimat T. (2008b), LC-MS and LC-PDA vs. phytochemical analysis of Colchicum brachyphyllum. Pharmazie 63, 860-865.

Carmona M., Zalacain A., Sanchez A. M., Novella J. L., and Alonso G. L. (2006), Crocetin esters, picrocrocin and its related compounds present in Crocus sativus stigmas and Gardenia jasminoides fruits. Tentative identification of seven new compounds by LC-ESIMS. J. Agric. Food Chem. 54, 973-979.

Chommadov B., Yusupov M., and Sadykov A. (1990), Photochemical isomers of tropolone alkaloids. Chem. Nat. Compd. 26, 113-128.

Corley D. G. and Durley R. C. (1994), Strategies for database dereplication of natural products. J. Nat. Prod. 57, 1484-1490.

Freyer A., Zarga M. A., Firdous S., Guinaudeau H., and Shamma M. (1987), Five new alkaloids from Colchicum ritchii. J. Nat. Prod. 50, 684-689.
Ghisalberti E. L. (1993), Detection and isolation of bioactive natural products. In: Bioactive Natural products: Detection, Isolation and Structural Determination (Colegate S. M. and Molyneux R. J., eds.). CRC Press, Inc., Boca Raton, FL, USA, pp. 9-57.

Hostettmann K., Wolfender J., and Terreaux C. (2001), Modern screening techniques for plant extracts. Pharm. Biol. 39, 18-32.

Jin M., Yang Y., Su B., and Ren Q. (2006), Rapid quantification and characterization of soya saponins by high-performance liquid chromatography coupled with electrospray mass spectrometry. J. Chromatogr. A 1108, 31-37.

Kingston D. G. I. (1996), Natural products as pharmaceuticals and sources for lead structures. In: The Practice of Medicinal Chemistry (Meyer P., ed.). Academic Press, London, pp. 101-116.

Liau B., Jong T., Lee M., and Chen S. (2007), LC-APCIMS method for detection and analysis of tryptanthrin, indigo, and indirubin in Daqingye and Banlangen. J. Pharm. Biomed. Anal. 43, 346-353.

Liu A., Guo H., Ye M., Lin Y., Sun J., Xu M., and Guo D. (2007), Detection, characterization and identification of phenolic acids in Danshen using high-performance liquid chromatography with diode array detection and electrospray ionization mass spectrometry. J. Chromatogr. A 1161, 170-182.

O’Neil M. J., Smith A., and Heckelman P. E. (2001), The Merck Index, 13th ed. Merck Research Laboratories, Division of Merck and Co., Inc., White House Station, NJ.

Petsalo A., Jalonen J., and Tolonen A. (2006), Identification of flavonoids of Rhodiola rosea by liquid chromatography-tandem mass spectrometry. J. Chromatogr. A 1112, 224-231.

Potesilova H., Dolejs L., Sedmera P., and Santavy F. (1977), Substances from plants of subfamily Wurmbaeoideae and their derivatives 83 . Constitution of 3 alkaloids (10,11-epoxycolchicine, colchiciline and 3 -demethyl- $N$-deacetyl- $N$-formylcolchicine) isolated from seeds of Colchicum-latifolium. Collect. Czech. Chem. Commun. 42, 1571-1580.

Rosso A. and Zuccaro S. (1998), Determination of alkaloids from the colchicine family by reversed-phase high-performance liquid chromatography. J. Chromatogr. A 825, 96-101.

Roth L., and Rupp G. (1995), Roth Collection of Natural Products Data. VCH, Weinheim, Germany.

Sarker S. D. and Nahar L. (2012), Hyphenated techniques and their applications in natural products analysis. Methods Mol. Biol. 864, 301-340.

Turdikulov Kh., Yusupov M., Aslanov Kh., and Sadykov A. (1974), Structure of crociflorinone. Chem. Nat. Compd. 10, 844-845.

Wolfender J., Ndjoko K., and Hostettmann K. (2003), Review: Liquid chromatography with ultraviolet absorbance-mass spectrometric detection and with nuclear magnetic resonance spectroscopy: a powerful combination for the on-line structural investigation of plant metabolites. J. Chromatogr. A 1000, 437-455. 